\title{
A ORDEM DO DIA
}

\section{THE ORDER OF THE DAY}

\section{L'ORDRE DU JOUR}

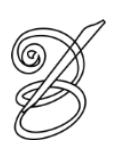

Traduzido por:

Sandra Mara STROPARO ${ }^{i *}$

Universidade Federal do Paraná

Curitiba, Paraná, Brasil

Resumo: O texto apresenta um excerto da tradução do livro A ordem do dia, de Éric Vuillard. O trecho é um bom exemplo do trabalho refinado de narração construído ao longo do livro, pois o olhar de quem narra passeia perto por um acontecimento histórico, o início da ascensão nazista na Alemanha, de um dos presentes a outro, aproximando-se ou distanciando-se conforme o momento, sem deixar de, muito sutilmente, estabelecer uma perspectiva irônica e crítica.

Palavras-chave: Literatura francesa. Tradução. História do nazismo.

Abstract: The piece presents an excerpt of the translation for the book L'Ordre du Jour, by Éric Vuillard. This section is a good example of the refined narration technique built throughout the book since the regard of this voice glances by a historical event, the beginnings of Nazi ascension to power in Germany, going from one of the participants to the other, getting closer or pulling away from the moment to moment, still managing to establish, very subtly, an ironical and critical perspective.

Keywords: French literature. Translation. History of nazism. 


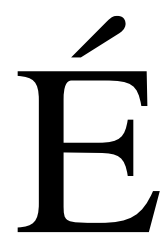

ric Vuillard nasceu em maio de 1968 e hoje é escritor e roteirista de cinema. Sua obra literária, já extensa, iniciou-se em 1999, com Le Chasseur. Uma parte considerável de seus romances é de reconstrução, crítica e comentário histórico. Em A Ordem do Dia ii, em uma narrativa construída de forma aparentemente incerta, como se nunca soubéssemos com certeza quem é o narrador e qual seu lugar naquela história — gerando com isso inseguranças em relação ao discurso elaborado: verdade? memória revisada? —, constrói a história política da Alemanha do final dos anos 30, mostrando o pacto sórdido entre grandes empresários e o partido Nazista e como isso possibilitou a $2^{\mathrm{a}}$ Guerra Mundial. Essa obra, impactante e com forte significado para o momento político contemporâneo, recebeu o prêmio Goncourt de 2017. 
De repente, as portas rangem, as tábuas do chão rilham; conversam na antessala. Os vinte e quatro lagartos se levantam sobre suas patas de trás e ficam bem direitos. Hjalmar Schacht engole sua saliva, Gustav arruma seu monóculo. Atrás das folhas da porta, ouvem-se vozes abafadas, depois um assobio. E enfim, o presidente do Reichstag penetra na peça, sorrindo; é Hermann Goering. E isso, bem longe de nos surpreender, é no fundo apenas um acontecimento bastante banal, rotineiro. No mundo dos negócios, as lutas entre partidos não são nada. Políticos e industriais costumam se frequentar.

Goering fez então a volta na mesa, com uma palavra para cada um, segurando a mão de cada um com um aperto indulgente. Mas o presidente do Reichstag não veio somente acolhêlos, ele regouga algumas palavras de boas-vindas e evoca logo as próximas eleições de 5 de março. As vinte e quatro esfinges o ouvem atentamente. A campanha eleitoral que se anuncia é determinante, declara o presidente do Reichstag, é preciso acabar com a instabilidade do regime; a atividade econômica demanda calma e firmeza. Os vinte e quatro senhores balançam religiosamente a cabeça. As velas elétricas do lustre piscam mais que há pouco. E se o partido nazista conseguir a maioria, acrescenta Goering, estas eleições serão as últimas para os dez anos seguintes; e até mesmo - acrescenta com uma risada - por cem anos.

Um movimento de aprovação percorreu o ambiente. No mesmo momento, houve alguns barulhos de portas e o novo chanceler enfim entrou no salão. Aqueles que nunca o tinham encontrado estavam curiosos para vê-lo. Hitler estava sorridente, descontraído, nada do que imaginavam, afável, sim, até amável, bem mais amável do que teriam acreditado. Houve para cada um uma palavra de agradecimento, um aperto de mão vigoroso. Uma vez feitas as apresentações, cada um retomou seu lugar em sua poltrona confortável. Krupp se encontrava na primeira fileira, cutucando com um dedo nervoso seu minúsculo bigode; logo atrás dele, dois dirigentes da IG Farben, mas também von Finck, Quandt e alguns outros cruzaram doutamente as pernas. Houve uma tosse cavernosa, uma tampa de caneta fez um minúsculo click. Silêncio.

Eles ouviram. O fundo da proposta se resumia a isso: era preciso acabar com um regime fraco, afastar a ameaça comunista, suprimir os sindicatos e permitir a cada patrão ser um Führer em sua empresa. O discurso durou uma meia hora. Quando Hitler terminou, Gustav se levantou, deu um passo à frente e, em nome de todos os convidados presentes, agradeceu a ele por ter enfim esclarecido a situação política. $\mathrm{O}$ chanceler deu uma rápida volta na pista antes de ir embora. Era congratulado, mostravam-se corteses. Os velhos industriais pareciam aliviados. Assim que ele se retirou, Goering tomou a palavra, reformulando energicamente algumas ideias, depois evocou de novo as eleições de 5 de março. Esta seria uma ocasião única de sair 
do impasse em que se achavam. Mas para fazer campanha, era preciso de dinheiro: ora, o partido nazista não tinha mais um tostão e a campanha eleitoral se aproximava. Nesse instante, Hjalmar Schacht se levantou, sorriu para a assembléia e proferiu: "E agora, senhores, ao caixa!"

Esse convite, certamente pouco cavalheiresco, não tinha nada de novo para esses homens; eles estavam acostumados com os molha-mãos e as ajudinhas. A corrupção é um item incompreensível no orçamento das grandes empresas, tendo vários nomes: lobby, gratificações de final de ano, financiamento de partidos. A maioria dos convidados verteu em seguida algumas centenas de milhares de marcos, Gustav Krupp doou um milhão, Georg von Schnitzler quatrocentos mil, e recolheu-se assim uma soma considerável. Essa reunião de 20 de fevereiro de 1933, em que se podia ver um momento único da história patronal, um compromisso inaudito com os nazistas, é para os Krupp, os Opel, os Siemens só um episódio muito comum da vida dos negócios, uma banal angariação de fundos. Todos sobreviverão ao regime e financiarão no futuro muitos partidos na proporção de sua performance.

Mas para melhor compreender o que é a reunião de 20 de fevereiro, para tocar seu fundo de eternidade, é preciso a partir de agora chamar esses homens pelos seus nomes. Não são mais 342 Günther Quandt, Wilhelm von Ople, Gustav Krupp, August von Finck que estão lá, neste fim de tarde, em 20 de fevereiro de 1933, no palácio do presidente do Reichstag; são outros os nomes que devem ser pronunciados. Porque Günther Quandt é um criptônimo, ele dissimula um coisa bem diferente daquele homem gordo cofiando os bigodes e que se mantém gentilmente em seu lugar, em volta da mesa de honra. Atrás dele, justo atrás dele, se encontra uma silhueta, ao contrário, imponente, sombra tutelar, tão fria e impenetrável quanto uma estátua de pedra. Sim, sobrepondo-se com toda sua força, feroz, anônima, à figura de Quandt, e dando-lhe esta rigidez de máscara, mas de uma máscara que colaria no rosto melhor que sua própria pele, adivinha-se sobre ele: Accumulatoren-Fabrik AG, a futura Varta, que conhecemos, já que as pessoas jurídicas têm seus avatares, como as divindades antigas tomavam diversas formas e, ao longo do tempo, incorporavam outros deuses.

Esse é, portanto, o autêntico nome de Quandt, seu nome de demiurgo, já que ele, Günther, é apenas um montinho de carne e ossos, como você e eu, e depois dele seus filhos e os filhos de seus filhos se sentarão no trono. Mas o trono, esse, permanece, quando o montinho de carne e ossos apodrecer na terra. Assim, os vinte e quatro não se chamam nem Schnitzler, nem Witzleben, nem Schmitt, nem Finck, nem Rosterg, nem Heubel, como a certidão civil nos incita a crer. Eles se chamam BASF, Bayer, Agfa, Opel, IG Farben, Siemens, Allianz, Telefunken. Sob esses nomes, nós os conhecemos. Nós os conhecemos até muito bem. Eles 
estão lá, no meio de nós, entre nós. São os nossos carros, nossas máquinas de lavar, nossos produtos de entretenimento, nossos rádios-relógios, o seguro da nossa casa, a bateria de nosso relógio de pulso. Eles estão lá, em todos os lugares, sob a forma de coisas. Nosso cotidiano é deles. Eles cuidam de nós, nos vestem, nos iluminam, nos transportam pelas estradas do mundo, nos fazem adormecer. E os vinte e quatro homens presentes no palácio do presidente do Reichstag, neste 20 de fevereiro, são apenas seus mandatários, o clero da grande indústria; são os sacerdotes de Ptá. E eles se mantêm lá, impassíveis, como vinte e quatro máquinas de calcular nas portas do Inferno.

\section{REFERÊNCIA}

VUILLARD, Eric. A ordem do dia. São Paulo: Editora Tusquets, 2019. Tradução de: L'Ordre du jour. p. 20-25

\footnotetext{
i* Sandra Mara STROPARO - Licenciada em Letras Francês (1992) pela Universidade Federal do Paraná. Mestre em Letras (1995) pela mesma instituição. Doutora em Literatura (2012) pela Universidade Federal de Santa Catarina. Professora adjunta na Universidade Federal do Paraná. Universidade Federal do Paraná, Setor de Ciências Humanas, Letras e Artes, Departamento de Literatura e Linguística. Curitiba, Paraná, Brasil Currículo acadêmico: http://lattes.cnpq.br/6217238996446650 ORCID: https://orcid.org/0000-0002-2129-1498 E-mail: smstroparo@gmail.com ii A tradução foi autorizada pelo diretor editorial da Editora Planeta, Cassiano Elek Machado, em 11 de setembro de 2019, via e-mail para a tradutora.
} 